\title{
Transtornos de Aprendizagem na visão dos Professores
}

\author{
Mônica Maria Siqueira Damasceno ${ }^{1}$, Annatália Menezes de Amorim Gomes ${ }^{2}$
}

\begin{abstract}
Resumo: O presente artigo é fragmento da dissertação de mestrado intitulado a câmera do olhar e o olhar da câmera: percepções dos professores acerca dos transtornos e dificuldades de aprendizagem na arte da ensinagem. Aprendizagem é contínua e bem intensa na criança e no adolescente, sendo peculiar a cada fase, podendo esse processo ser desenvolvido tranquilamente ou de forma conturbada. Diante disso, é importante que os professores percebam em sala de aula as características dos Transtornos e Dificuldades de Aprendizagem quando apresentadas, para que possam desenvolver estratégias ativas e eficazes de aprendizagem para estes estudantes. O estudo teve como objetivo: Compreender os significados e práticas dos professores acerca dos Transtornos e Dificuldades da Aprendizagem na escola. Tratou-se de um estudo de natureza qualitativa, utilizando como método para coleta de dados o Grupo Focal-GF. Para a discussão dos dados, foi utilizada a Técnica de Análise de Conteúdo. Este artigo irá apresentar os resultados obtidos nas categorias: O Processo Ensino Aprendizagem e suas características: uma "via de mão dupla" na formação humana e Desconhecendo um provável TA e os desafios de lidar com as diferenças. Os sujeitos participantes foram 10 (dez) professores de uma Instituição Federal de Educação, de ambos os sexos. A investigação possibilitou concluir que: a percepção dos professores ainda é insuficiente quanto ao assunto proposto, bem como os conhecimentos sobre a diferenciação entre as nomenclaturas Dificuldade e Transtorno, seus tipos e causas. No processo ensino aprendizagem, percebe-se que há um grande desejo de alguns de se ter uma prática que não seja unilateral. Quanto aos desafios enfrentados pelos professores em sala de aula, o maior deles é lidar com as grandes diferenças encontradas neste ambiente, com relação aos níveis de aprendizagem e às limitações do tempo e estrutura do sistema educacional. Esta pesquisa revelou que os professores, sejam eles bacharéis ou licenciados, possuem uma limitação sobre como perceber os estudantes que possuem uma ruptura na sua aprendizagem.
\end{abstract}

Palavras- chave: Práticas de ensino - Dificuldades; Professor; Aprendizagem.

\section{Learning Disorders in the View of Teachers}

\begin{abstract}
This article is a fragment of the dissertation titled: The camera look and the look of the camera : perceptions of teachers about the disorders and learning disabilities in the art of teaching. Learning is continuous and very intense in children and adolescents, and is peculiar to each phase, this process may be developed or quietly troubled way. Therefore, it is important that teachers understand in classroom the characteristics of Disorders and Learning Disabilities when presented, so they can develop active and effective learning strategies for these students. The study aimed to: Understand the meanings and practices of teachers about the Difficulties of Learning Disorders and at school. This was a qualitative study, using as a method to collect the Focal-GF Group data. For a discussion of the data, the technique of content analysis was used. This article will present the results obtained in the categories: The Teaching Learning Process and its characteristics: a 'two-way street "in human development and a likely Unaware TA and the challenges of dealing with differences. The subjects were ten (10) teachers of Federal Education Institution, of both genders. The investigation led us to conclude that the perception of teachers is still insufficient on the proposed subject, as well as knowledge about the differentiation
\end{abstract}

\footnotetext{
${ }^{1}$ Pedagoga, Professora do Instituto Federal do Ceará - IFCE, Mestre em saúde da Criança e do Adolescente pela Universidade Estadual do Ceará - UECE. Especialista em psicologia Aplicada à Educação pela Universidade Regional do Cariri - URCA. E-mail: siqueiramonica@hotmail.com;

${ }^{2}$ Doutora em Ciências da Saúde pela UFRN. Mestre em Educação em Saúde pela Universidade de Fortaleza. Graduada em Psicologia pela UFC. Professora colaboradora do Mestrado de Saúde Pública e Mestrado em Saude da Criança e Adolescente da Universidade Estadual do Ceará. Email: annataliagomes@gmail.com
} 
between difficulty and disorder classifications, their types and causes. In teaching learning process, one realizes that there is a great desire of some to have a practice that is not unilateral. On the challenges faced by teachers in the classroom, the biggest one is dealing with the large differences found in this environment with respect to the levels of learning and to time constraints and structure of the educational system. This research revealed that teachers, whether graduates or licensed, have a limitation on how students perceive they have a break in their learning.

Key word: Teaching practices - Difficulties; teacher; Learning.

\section{Introdução}

A arte da aprendizagem é contínua e intensa na criança e no adolescente, sendo peculiar a cada fase do ciclo da vida, podendo esse processo ser desenvolvido tranquilamente ou de forma conturbada. Diante disso, é importante que os professores percebam nos estudantes, desde o início da fase escolar, as características das Dificuldades de Aprendizagem (DA) e dos Transtornos ou Distúrbios de Aprendizagem (TA). Isso se torna possível porque neste período espera-se que a criança já consiga ler, escrever, soletrar e calcular, desde que ela já tenha passado pelos processos de aquisição destas habilidades e possua idade cronológica adequada para tal.

Rebelo (2001) afirma que as dificuldades de aprendizagem podem ser entendidas como obstáculos ou barreiras encontradas por alunos durante o período escolar, no que diz respeito ao recebimento e assimilação dos conteúdos propostos. Além disso, podem gerar ou precipitar o aparecimento de problemas emocionais, comportamentais, familiares e sociais em diferentes graus de gravidade, comprometendo ainda mais o processo de aprender. Surge então uma inquietação: será que ao aparecerem estes obstáculos na vida dos estudantes, os professores associam seus comportamentos a um Transtorno ou Dificuldade de Aprendizagem?

Segundo Davis e Oliveira (2010), na escola a criança (estudante) sofre uma transformação radical em sua forma de pensar. Antes, os conhecimentos são assimilados de modo espontâneo, a partir da experiência direta. Quando ela ingressa na escola, existe uma intenção prévia de organizar situações que propiciem o aprimoramento dos processos de pensamento e da própria capacidade de aprender. $\mathrm{O}$ papel do professor nesse processo é fundamental. Por isso é importante que ele conheça as Teorias da Aprendizagem, bem como os Transtornos e Dificuldades da Aprendizagem, para que tenha uma posição clara e definida sobre sua prática pedagógica e possa tomar decisões coerentes.

Um aspecto que pode interferir no processo de escolarização e nas dificuldades de aprendizagem, de acordo com Proença (2002), é o despreparo profissional do professor, que é fruto de um sistema educacional que não prioriza ou não dá a devida atenção à qualidade necessária na formação do docente. 
[...] Como especialistas no campo de aprendizagem, torna-se fundamental conhecer o conjunto de leis que regem o processo de construção do conhecimento em geral, bem como os inerentes à construção de cada área do conhecimento particular. Somente e na medida em que conhecemos as leis que caracterizam sua origem e evolução, podemos diferenciar aquilo que se constitui como sintomático daquilo que faz parte das normas inerentes ao processo de construção. (BOSSA, 2010, p. 9).

Diante desta citação, é possível perceber o quanto é imprescindível ao professor conhecer e compreender o processo de desenvolvimento do indivíduo, buscando verificar através de observações constantes em sala de aula, as evoluções de seus alunos, podendo desta forma, diferenciar o que se constitui um sintoma de algum transtorno, daquilo que faz parte do processo de construção e consolidação do desenvolvimento.

O comportamento de uma criança ou adolescente com algum transtorno difere das crianças e adolescentes comuns, por não prosperarem em seus afazeres, ficam desmotivadas e com a autoestima abalada, o que ocasiona também frustração e a aprendizagem não se efetiva.

Segundo Rohde et al. (2000), as intervenções no âmbito escolar são muito importantes, tendo como foco o desempenho escolar. Dessa forma, os professores deveriam ser orientados a terem conhecimentos sobre as necessidades especiais destes estudantes, como por exemplo, salas de aula bem estruturadas, com poucos alunos, rotinas diárias consistentes, ambiente escolar previsível, tarefas propostas que não sejam demasiadamente longas e que devem ser explicadas passo a passo. Diante dessas e outras informações é possível o professor desenvolver estratégias ativas e eficazes de aprendizagem para estes estudantes.

Smith e Strick (2003) afirmam que a característica principal de uma dificuldade de aprendizagem é o baixo rendimento, ou desempenho, em atividades de leitura, escrita ou cálculo matemático apresentado por escolares em relação ao que se poderia esperar de acordo com sua inteligência e oportunidades.

Embora o baixo rendimento ou desempenho escolar não seja definitivo para caracterizar um transtorno de aprendizagem, é necessário que os pais e professores estejam atentos a este, pois o mesmo representa o ponto de partida para a detecção de problemas relacionados à leitura, à escrita $\mathrm{e}$ ao cálculo-matemático.

Os Transtornos da Aprendizagem mais conhecidos são: Transtorno de Leitura (Dislexia), o Transtorno da Matemática (Discalculia), o Transtorno da Expressão Escrita (Disortografia e Disgrafia).

Quando se entende o que é um transtorno de aprendizagem, suas causas e consequências, os professores passam a compreender os fatores que ocasionam determinados comportamentos. Sendo assim, terão mais condições de aplicar as mudanças necessárias para tratar o comportamento indesejável do estudante. 
O professor que não conhece os problemas relacionados aos transtornos corre o risco de fazer um julgamento equivocado acerca daquele estudante, como por exemplo, rotulá-lo de preguiçoso, desligado, bagunceiro, deficiente, problemático, entre outros.

Barbosa (2006) coloca que, se algum estudante não aprende, cabe ao professor, antes de rotulá-lo de desinteressado, de portador de dificuldades, deficiente e outros, perguntar-se o que está fazendo para incentivar seus alunos, ou incitar neles uma ação em direção a uma meta que eles próprios buscarão atingir.

O professor é peça fundamental no desempenho e sucesso escolar dos estudantes e a forma como ele vai conduzir suas aulas poderá assegurar a estes possuidores de alguma dificuldade na aprendizagem, um desenvolvimento cognitivo, emocional e social equilibrado e construtivo.

Embora possua um papel importante no processo de identificação e descoberta de algum transtorno de aprendizagem, vale ressaltar que o professor não possui formação específica para fazer tais diagnósticos, os quais devem ser feitos por profissionais como médicos, psicólogos, e psicopedagogos, entre outros. O papel do professor deverá ser o de observar o estudante e auxiliar no seu processo de aprendizagem, e caso perceba necessidade, encaminhá-lo a um profissional habilitado para tal.

\section{Transtornos e dificuldades da aprendizagem: aspectos históricos, causas e tipos}

Se compreendermos aprendizagem como um processo do indivíduo para a obtenção de habilidades e competências que possibilitem o seu bom desempenho e reciprocidade com o mundo que o cerca, podemos então considerar que os transtornos ou dificuldades de aprendizagem ocorrem quando essas competências e habilidades não são atingidas. As causas para que isso ocorra podem ser as mais diversas e um dos papéis dos educadores é possuir a capacidade de reconhecer e discernir as verdadeiras causas dessas dificuldades.

De acordo com Scoz (2004, p. 19-20), não é fácil encontrar uma definição clara e abrangente para "problema de aprendizagem". Durante muitos anos o enfoque orgânico orientou a reflexão dos educadores e terapeutas que lidavam com essa questão. Esse enfoque surgiu por volta dos séculos XVIII e XIX, com o grande desenvolvimento das ciências médicas e biológicas, especialmente da Psiquiatria. Datam dessa época os estudos de neurologia, neurofisiologia e neuropsiquiatria, conduzidos em laboratórios anexos a hospícios, e a rígida classificação dos pacientes dessas instituições como anormais. Posteriormente, o conceito de anormalidade começou a ser transferido dos hospitais para as escolas: as crianças que não acompanhavam seus colegas na aprendizagem passaram 
a ser designadas como anormais escolares, já que seu fracasso era atribuído a alguma anormalidade orgânica.

Segundo Sisto e Martineli (2006), mesmo com o reconhecimento por parte dos educadores, psicólogos e psiquiatras acerca da importância de outras abordagens como a Psicologia comportamental, cognitiva e os processos afetivos emocionais, a visão organicista, no entanto, sempre prevaleceu sobre a educativa, reabilitadora e psicológica.

Na década de 1960, o termo dificuldade de aprendizagem disputava com o conceito de transtorno de aprendizagem. No ano de 1965, surgia nos EUA a Associação Nacional para Crianças com Dificuldades de Aprendizagem. Em seguida, outras foram aparecendo durante a década de 1970. As dificuldades de aprendizagem constituíam um fenômeno social que terminou na metade dos anos 1970, classificado como distúrbio, dando ênfase aos problemas de leitura e linguagem.

Na década de 1980, a questão voltou a ser considerada de forma mais abrangente, e foram incluídos, além dos problemas de leitura, os da escrita. A partir de 1990, pesquisadores norte-americanos começaram a considerar a dimensão social do problema, tomando mais consciência e conhecimento da questão, o que resultou na melhoria das técnicas de diagnóstico e numa maior aceitação social do fenômeno.

A expressão "DA" surgiu como uma necessidade, na medida em que as crianças diagnosticadas com disfunção cerebral mínima (minimal brain disfunction), com dislexia e outros "rótulos" similares eram, em alguns casos, tão diferentes entre si, e tão distintas das crianças deficientes mentais que exigiam uma definição mais abrangente e transdisciplinar do que a tradicional avaliação médica psicométrica. (FONSECA, 2005, p. 287).

Segundo Carneiro, Martinelli e Sisto (2003, p. 149): a história da educação brasileira vem sendo marcada por uma crescente preocupação em se tentar explicar o fracasso escolar, o qual tem sido denunciado pelos altos índices de repetência e evasão, ocorridos nos últimos anos.

Para Almeida (2002), as Dificuldades de aprendizagem podem causar evasão escolar, visto que o aluno desmotivado e com um número considerável de fracasso escolar está inclinado a abandonar o ambiente hostil que lhe causa sofrimento. A autora ainda coloca que os indicadores de evasão escolar são facilmente encontrados no Brasil, o que não ocorre com as Dificuldades de Aprendizagem.

Estudos apontam que os estudantes que ingressaram no $1^{\circ}$ ano do ensino fundamental, $60 \%$ não chegam a terminar o $9^{\circ}$ ano, 24\% são excluídos ou abandonam a escola nas primeiras séries, $97 \%$ repetem o ano escolar em alguma série do ensino básico e apenas 4,5\% conseguem terminar o $9^{\circ}$ ano sem nunca ter repetido (CARNEIRO, MARTINELLI, SISTO, 2003). No Brasil, cerca de $40 \%$ das crianças em séries iniciais de alfabetização apresentam dificuldades escolares. (SCHIRMER; FONTOURA; NUNES, 2004) 
Segundo Rotta (2006, p. 127), a prevalência dos transtornos de aprendizagem varia de 2 a 10\%, e de acordo com a autora, a importância dada aos transtornos do desenvolvimento das habilidades escolares se deve ao fato de que o sucesso na vida do indivíduo está ligado ao bom desempenho escolar.

A Associação de Psiquiatria Americana - APA (2002) estima que nos países em que a educação é precária e de pouca qualidade, as prevalências dos transtornos de aprendizagem podem ser superiores a 10\%. No ano de 2009, a avaliação realizada pelo Programa Internacional de Avaliação de Alunos PISA mostrou que 20,3\% dos alunos do ensino médio eram analfabetos funcionais, ou seja, são capazes de identificar letra, frases e palavras, mas não compreendem o que leem. Ainda de acordo com o último relatório divulgado pelo Instituto Brasileiro de Geografia e Estatística (IBGE, 2010), 9,7\% da população não sabem ler e escrever.

É de suma importância termos acesso a essas informações, pois o professor que irá avaliar uma criança com problemas de aprendizagem deverá saber que muitos estudantes que não têm uma aprendizagem satisfatória, não sofrem necessariamente de transtorno de aprendizagem, e sim de um grave problema metodológico de ensinagem. Mais uma vez apontamos a importância de se conhecer as características de uma dificuldade de aprendizagem e de um transtorno, para que se possa fazer uma avaliação correta acerca do real motivo do não aprender.

Quando se procuram as causas reais dos Transtornos de Aprendizagem, não encontramos uma resposta definitiva, porém, O CID-10 esclarece que a etiologia dos Transtornos de Aprendizagem não é conhecida, mas que há "uma suposição de primazia de fatores biológicos, os quais interagem com fatores não-biológicos".

A necessidade de um olhar aprofundado e de uma leitura minuciosa é que dificuldade e transtorno ainda podem nos confundir acarretando assim um prejuízo ao aluno no que diz respeito à forma como o professor conduz a sua aprendizagem. Já tendo compreendido um pouco sobre as prováveis causas dos transtornos, é importante que se apresentem os tipos mais conhecido de TAs.

A Classificação de Transtornos Mentais e de Comportamento da Classificação Internacional de Doenças - 10 (ou, simplesmente CID - 10) situa os problemas referentes à aprendizagem na classificação Transtornos específicos do desenvolvimento das habilidades escolares (F81)- Transtornos nos quais as modalidades habituais de aprendizado estão alteradas desde as primeiras etapas do desenvolvimento. O comprometimento não é somente a consequência da falta de oportunidade de aprendizagem ou de um retardo mental, e ele não é devido a um traumatismo ou doença cerebral.

Os Transtornos da Aprendizagem mais conhecidos são: Transtorno de Leitura (Dislexia), o Transtorno da Matemática (Discalculia), o Transtorno da Expressão Escrita (Disortografia e Disgrafia), bem como o TDAH. 


\section{Desenho metodológico}

Tipo de estudo - A escolha pela linha de pesquisa qualitativa se deu em função da sua característica de trabalhar com valores, crenças, representações, hábitos, atitudes, significados, significações, ressignificações, representações psíquicas e sociais, simbolizações, simbolismos, percepções, pontos de vista, perspectivas, vivências, experiências de vida e analogias (MINAYO, 2010). Corresponde, assim, a um espaço mais profundo de relações, dos processos e dos fenômenos que não podem ser reduzidos a operacionalização de variáveis.

Procedimentos de coleta de dados- Os dados foram obtidos por intermédio da técnica do Grupo Focal - GF, e de um Roteiro de Caracterização dos Sujeitos. O GF foi a técnica escolhida, pois se caracteriza como um procedimento de coleta de dados no qual o pesquisador tem a possibilidade de ouvir vários sujeitos ao mesmo tempo, além de observar as interações características do processo grupal. Tem como objetivo obter uma variedade de informações, sentimentos, experiências, representações de pequenos grupos acerca de um tema determinado (KIND, 2004).

De acordo com Abreu, Baldanza e Goldim (2009), os grupos focais fundam-se no desenvolvimento de entrevistas grupais, porém são mais do que simples entrevistas que levam em consideração apenas as respostas individuais de cada membro do grupo. No GF há uma interação grupal que faz com que os participantes discutam e manifestem suas opiniões gerando uma sucessão de dados, produzidos pela interação que revelem pontos de consenso e dissenso, fundamentais para dar resposta às indagações da pesquisa.

Organização e estruturação do Grupo Focal (GF)- Quanto à organização e estruturação do GF, contou de uma sessão, e no intervalo de quinze dias foi realizada uma segunda sessão. Os sujeitos da pesquisa foram professores que apresentavam características comuns, o que representou uma amostra intencional.

O campo de pesquisa foi uma Instituição Federal de Educação, localizada na região Centro Sul do Ceará. Este cenário foi escolhido por ser uma Instituição educacional que trabalha com adolescentes e a pesquisadora fazer parte do quadro permanente de professores, o que permite acesso aos estudantes, inclusive aos que apresentam um comportamento diferenciado do padrão, bem como observar o cotidiano dos professores desta Instituição, seja em sala de aula ou no ambiente escolar, o que terminou por gerar algumas inquietações sobre a relação ensino aprendizagem com alunos com prováveis TA. 
Sujeitos da pesquisa - Para esta pesquisa, o número de participantes do GF foi de dez (10), seguindo a orientação de Debus (2004),o quail estabelece uma variação de 8 (oito) a 10 (dez) participantes.

O GF foi estruturado por sujeitos com multicaracterísticas, entre as quais professores do sexo masculino e feminino; licenciados e bacharéis; professores com idades que variavam de 30 a mais de 50 anos e tempo de docência que foi de dois anos e acima de 15 anos.

O projeto foi submetido à análise do Comitê de Ética em Pesquisa (CEP) da Universidade Estadual do Ceara (UECE), onde foi avaliado e recebeu parecer favorável com No 356.956.

Organização e interpretação dos dados- Os dados foram analisados por meio da análise temática de Minayo (2010), por ser considerado um instrumento adequado ao discurso de conteúdo variável, como no caso desse estudo. Esta autora preocupa-se com um nível de realidade que não pode ser quantificado, ou seja, ela trabalha com o universo de significados, motivos, aspirações, crenças, valores e atitudes, o que corresponde a um espaço mais profundo das relações.

Deste modo, Minayo (2010, p. 316) afirma que:

Fazer uma análise temática consiste em descobrir os núcleos de sentido que compõem uma comunicação cuja presença ou frequência signifiquem alguma coisa com o objetivo analítico visado. Qualitativamente a presença de determinados temas denota os valores de referência e os modelos de comportamentos presentes no discurso.

Os resultados coletados foram analisados a partir desse entendimento, o que possibilitou apreender diversas questões vivenciadas no cotidiano dos professores acerca da percepção sobre os transtornos e dificuldades de aprendizagem. Cabe ressaltar que o senso comum elabora, comunica e partilha diversas representações sobre esse tema.

\section{Resultados e discussão}

Caracterização dos sujeitos do estudo - A amostra estudada foi formada por 10 sujeitos, sendo que $60 \%$ corresponderam ao sexo feminino, enquanto $40 \%$ eram do sexo masculino. Estes resultados confirmam os dados divulgados pelo observatório do Plano Nacional de Educação - PNE, segundo os quais as mulheres compõem $81,5 \%$ de professores da educação básica no País. Quanto à faixa etária, $20 \%$ consistiram nas idades entre 20 e 30 anos e de 41 a 50 anos; $50 \%$ dos sujeitos tinham idades entre 31 e 40 anos, o que representa um maior número de professores com estas idades; apenas $10 \%$ dos participantes possuíam idade acima de cinquenta anos. Com relação ao estado civil, pode-se dizer que $40 \%$ eram solteiros, $40 \%$ casados e $20 \%$ pertencem a outros tipos de relacionamento. 
Ao ser analisada a naturalidade dos participantes, encontrou-se que $60 \%$ são naturais do estado do Ceará, enquanto $40 \%$ são provenientes de outros estados.

De acordo com os dados pesquisados acerca da formação dos sujeitos, 30\% são licenciados, $40 \%$ possuem bacharelado e $30 \%$ cursaram tanto licenciatura quanto bacharelado. Com relação à formação continuada, $90 \%$ atingiram a pós-graduação strictu sensu e apenas $10 \%$ a pós-graduação lato sensu.

Quanto à formação, os dados mostram que o índice de bacharelado está bem compatível com a licenciatura, o que vai de encontro às falas dos sujeitos da pesquisa que colocam que os licenciados estão mais aptos a reconhecerem os alunos que possuem algum tipo de transtorno, ao contrário dos bacharelados.

Com relação à experiência em docência, $30 \%$ possuem experiência entre um a três anos; $30 \%$ acima de 15 anos, e $40 \%$ de quatro a oito anos. Isso mostra que todos os sujeitos já tiveram experiências com os comportamentos mais variados dos estudantes, e que entre esses é possível encontrar algum com TA. O tempo de experiência docente poderá ser um indicador de que esses sujeitos possuem percepções acerca dos TAs e DAs nos seus estudantes que os possibilitem ações adequadas.

O resultado mostra que $50 \%$ dos sujeitos apontam que o principal motivo que os levaram a serem professores foi o interesse pela profissão; $20 \%$ responderam que foi o mercado de trabalho; $20 \%$ movidos pelo desejo de contribuir com a sociedade e $10 \%$ devido a outros motivos.

Os dados mostram que um elevado percentual de professores nunca trabalhou com alunos que possuíssem algum TA (30\% já trabalharam e 70\% nunca trabalharam). Este resultado possui implicação direta quanto ao objetivo de identificar práticas específicas para estudantes que possuem algum TA, residindo neste ponto o primeiro fator limitador para este trabalho.

No tocante ao processo de atualização profissional relacionado à prática docente, nenhum professor participou de curso de qualificação ou aperfeiçoamento no período dos dois últimos anos. Quatro sujeitos concluíram seus mestrados e doutorados nos últimos dois anos.

Em seguida são apresentadas as categorias temáticas que emergiram a partir das falas dos sujeitos em interação no Grupo Focal.

CAT. I - o processo ensino aprendizagem e suas características: "uma via de mão dupla" na formação humana integral

No intuito de melhor conceber o processo ensino aprendizagem, foi-se em busca de uma literatura especializada em que é de fundamental importância o pensamento registrado pela UNESCO 
a qual apresenta os quatro pilares da educação, aprovado em relatório elaborado por Jacques Delors, cuja meta é propiciar as diretrizes básicas para o estímulo da aprendizagem ao longo da vida, favorecendo com isso o conhecimento.

\begin{abstract}
Aprender a conhecer, [...] O que também significa, aprender a aprender, para beneficiar das oportunidades oferecidas pela educação ao longo de toda a vida, sem se deixar cegar pelas pretensas verdades prontas e acabadas [...]; Aprender a fazer, a fim de adquirir, não somente uma qualificação profissional tecnicista, mas de uma maneira mais ampla desenvolver as potencialidades e competências [...]; Aprender a viver juntos, desenvolvendo a compreensão do outro e a percepção das interdependências e realizar projetos comuns é preparar-se para gerir conflitos no respeito pelos valores do pluralismo, da compreensão mútua e da paz; Aprender a ser, para melhor desenvolver a sua personalidade e estar à altura de agir com capacidade cada vez maior de autonomia, de discernimento e de responsabilidade pessoal, possibilitando que o indivíduo cresça, desenvolva-se vivendo em harmonia. (DELORS, 2003, p. 245).
\end{abstract}

Pode-se então chegar à conclusão de que aprender faz parte de um processo integrado. O processo de ensino aprendizagem voltado apenas para a absorção de conhecimento deverá dar lugar ao ensinar a pensar, ao conhecer, ao fazer e ser. Dessa forma, como coloca Delors (2003), o indivíduo se desenvolverá em uma totalidade, não negligenciando na educação as potencialidades de cada indivíduo: memória, raciocínio, sentido estético, capacidades físicas e aptidão para comunicar-se, entre outras.

Ainda segundo o autor, o processo de aprendizagem do conhecimento nunca está acabado, e pode enriquecer-se com qualquer experiência. Experiência esta ocorrida em processo dialético de intersubjetividades. Em busca destas inter-relações e, tentando detectá-lo ou não, partiu-se para os recortes das falas dos sujeitos. Destacando algumas que retratam o que os professores pensam sobre o processo de ensino aprendizagem.

Na perspectiva dos professores, o processo de aprendizagem é complexo, envolve a formação humana integral, constitui troca mútua de conhecimentos e saberes, e as motivações de professores e estudantes.

A partir da análise das falas dos sujeitos colhidas no GF, percebe-se a importância que os sujeitos da pesquisa dão ao processo de ensino aprendizagem, levando em consideração também o papel desempenhado pelo estudante, visto que os envolvidos no processo de ensino aprendizagem formam uma unidade. Como refere Mahoney e Almeida (2005), o processo ensino aprendizagem só pode ser analisado como uma unidade, pois ensino e aprendizagem são faces de uma mesma moeda; na relação interpessoal entre professor aluno é um fator determinante.

Percebem-se através do discurso dos sujeitos Perspectiva e Pacificadora seus posicionamentos quanto à relação ensino aprendizagem: $O$ ensino aprendizagem não tem aquela coisa de professor ensina e aluno aprende, é uma via agora de mão dupla [...] (Pacificadora). Este pensamento é corroborado pela fala do 
sujeito perspectivas: [...] hoje tem a questão da troca, a gente aprende muito, o que não é um processo unilateral, né? [...]. Diante das falas dos sujeitos percebe-se que os mesmos também consideram os estudantes como protagonistas no processo de ensino aprendizagem, se caracterizando numa relação mútua de conhecimento:

Ao se conhecer as concepções do processo ensino aprendizagem subjacentes à ação educativa, pode-se ter acesso aos princípios que norteiam a atuação do professor e do aluno neste percurso. $\mathrm{E}$ diante disso, como se vê na fala do sujeito Reconhecimento, a formação de valores não poderia estar de fora desse processo:

[...] o processo aprendizagem é bem complexo mesmo [...] a formação de ensino aprendizagem diz respeito a uma formação que não é só uma formação de conteúdo, é uma formação humana [...] é uma formação humana a processo de formação de valores (Reconhecimento).

Nos discursos dos sujeitos acima fica claro a reflexão dos seus fazeres pedagógicos no que se refere ao processo em si, que é complexo, porém vai além de uma formação escolar, envolve o ser humano como um todo; as características do processo de aprendizagem é uma "via de mão dupla" na formação humana. Como está dito nos quatro pilares e reconhecidos nas falas dos sujeitos, o processo de ensino aprendizagem não é meramente conteudista, mas deve-se ter em consideração também a formação humana integral.

Sobre isso, Maturana e Rezeka (2008, p. 11) colocam: "a formação humana, como tarefa educacional, consiste na criação das condições que guiam e apoiam o indivíduo em seu crescimento como um ser capaz de viver no auto respeito e no respeito pelo outro o que lhe proporciona aprender qualquer coisa e adquirir qualquer habilidade".

Para Gentili e Alencar (2001), educar hoje em dia não é só difícil, é também necessário. É humanizar o saber com o intuito de distribuí-lo e dar um sentido ético para a dignidade do ser humano. Aos educadores, cabe ensinar aos estudantes a olharem para fora e não só para dentro, a crescerem intelectualmente atentando para o que acontece ao seu redor.

Os professores, ao compartilharem suas perspectivas sobre ensino aprendizagem, manifestaram uma reflexão em torno do seu agir profissional na relação com o estudante no tocante a despertar a atenção do mesmo para o que é discutido, focar os assuntos no que interessa aos estudantes. 


\section{CAT. II- Desconhecendo um provável transtorno de aprendizagem e os desafios de lidar com a} diferença

Esta categoria trata da percepção dos professores acerca dos transtornos de aprendizagem no processo ensino aprendizagem, bem como a identificação dos tipos de transtornos.

O Grupo Focal revelou que os participantes da pesquisa conseguem perceber que algo não está dentro do comportamento padrão do desempenho "esperado" dos estudantes. Ao relatarem suas experiências com os mesmos comentaram situações vividas em sala de aula, porém não apresentaram isso como um provável transtorno de aprendizagem, e sim como comportamentos diferenciados dos demais.

Nas falas dos sujeitos do estudo observou-se um maior envolvimento com o tema, eles demonstraram querer falar de algum tipo de experiência que tiveram com algum estudante. No depoimento do entrevistado Conhecimento diz que: "eu acho que a identificação da dificuldade, do transtorno, é o primeiro passo [...]" Percebe-se que o educador é consciente do seu papel neste contexto. Sem esta identificação é bastante provável que os professores fiquem perdidos na sala de aula e os alunos em seus mundos internos.

No depoimento da Semeadora temos: "uns a gente não consegue detectar." Nesta fala o sujeito diz que consegue identificar, porém não especifica como esse procedimento é feito. Para isso, há necessidade de veicular nos meios de comunicação e formação de profissionais, informações básicas de identificação dos transtornos suficientes para possibilitar o entendimento da condição e minimizar os efeitos negativos de um "diagnóstico" equivocado.

Percebe-se um conhecimento na identificação do comportamento "fora do padrão", mas no que se refere às situações escolares de perceber, memorizar e ler, que exigem um funcionamento da atenção para que o aluno consiga dominar os conhecimentos trabalhados. Sendo assim, é essencial o conhecimento do educador na identificação precocemente, pois a escola é um espaço de socialização do conhecimento.

O professor assume um papel "fundamental" na vida escolar do estudante, sendo possível que reconheça a dificuldade que este "enfrenta" no dia a dia da escola. A prática docente necessita, então, acompanhar a "evolução" das dificuldades que se apresentam, entre elas os TAs.

Sisto (2003) coloca que ao professor não compete apenas conhecer as metodologias de ensino existentes, mas compreender seu estudante. Compreender em que nível de desenvolvimento ele se encontra, como são suas características de comportamento e como ele aprende. Com algum preparo e sensibilidade o professor estaria mais equipado do que os próprios pediatras, dispondo de maior oportunidade para detectar problemas cruciais na vida e no desenvolvimento dos estudantes. Deste 
modo, o preparo e o bom senso do professor são os elementos chave para que essas questões possam ser mais bem abordadas (BALONE; MOURA, 2008).

Os pesquisados expressaram que, em algum momento, já identificaram esses estudantes em sala de aula, principalmente por terem comportamentos diferenciados, como vimos na fala do sujeito Desbravadora: "eu identifico pelo jeito de falar, se comportar, retração, isolamento, dificuldade de escrever e aprender, é diferente dos outros

Ao considerar os discursos, percebe-se a tentativa dos sujeitos em entender o que acontece com os estudantes, porém cada um faz o seu "diagnóstico", sem na discussão chegarem a um consenso sobre o que realmente acontece com os mesmos. As falas mostram falta de embasamento teórico para associarem os comportamentos relatados, com algum tipo de transtorno da aprendizagem. Mazer et al. (2009) coloca que as pesquisas na área da educação apontam para a necessidade de atenção quanto aos problemas de aprendizagem.

É importante ressaltar que o problema não se encontra exclusivamente no professor, pois o modelo de educação que se apresenta não tem favorecido a inclusão das diferenças. O que se tem visto até agora são teorias bem formuladas e discutidas, sendo o modelo "ideal" para os estudantes, mas quando se vê a prática verificam-se as dificuldades encontradas na atuação do professor.

As mudanças na postura dos educadores se fazem necessárias, por exemplo, quando há necessidade de adaptações, cujas formações estão pautadas em paradigmas de racionalidade técnica, devem buscar a consciência da intencionalidade de seu fazer docente e estimular seu trabalho integrado pela reflexão conjunta (SILVA; VENANCIO, 2005). Cabe também destacar que, sem a colaboração, sem ser uma atividade coletiva, sem que se tenha uma mentalidade inclusiva, o êxito maior continuará sendo do discurso vazio e sem eco.

A Dislexia e a Hiperatividade são os TAs mais conhecidos pelos professores, embora a hiperatividade não se configure como um TA, mas é um dos transtornos que mais acarreta a reprovação. Ainda que reconheçam a existência desses transtornos, mais uma vez os sujeitos não demonstraram aprofundamento sobre o tema. Para Rotta (2006), o TA mais conhecido é a Dislexia, cuja leitura e escrita, muitas vezes, são incompreensíveis.

Estes TAs são comuns em sala de aula, e as suas características são bastante perceptíveis, os professores só precisam ficar atentos e verão que se algum estudante apresenta essas características (no mínimo seis e persistirem por no mínimo seis meses), há uma possibilidade de se ter um TA.

Conhecer o estudante nas suas dificuldades e potencialidades evita, por parte dos professores, considerar apenas os aspectos negativos dos estudantes e generalizar os mesmos como preguiçosos, doentes ou indisciplinados. Outro ponto a destacar é que não houve referências por parte dos sujeitos a ações pedagógicas específicas para alunos com um provável TA. A ausência dessas ações aponta para 
a necessidade de um trabalho integrado no processo ensino aprendizagem com os participantes da pesquisa.

O professor tem, entre outras, a missão de promover o ensino e a aprendizagem de alunos que, muitas vezes, têm um nível desigual de desenvolvimento, interesses, motivações e provêm de ambientes socioeconômicos e culturais diferentes.

\section{Considerações finais}

A pesquisa foi realizada com o intuito de investigar a percepção dos professores acerca dos TAs e DAs numa Instituição de Ensino Federal. Iniciou-se o trabalho partindo do princípio de que o professor que está em sala de aula possui pelo menos um conhecimento mínimo para trabalhar com estudantes que apresentem um baixo rendimento escolar devido a alguma lacuna no seu aprendizado, seja causado por uma DA ou até mesmo por um TA. Porém, no percurso e análise dos dados levantados os resultados apontaram que a percepção dos professores ainda é insuficiente quanto ao assunto proposto, bem como os conhecimentos sobre a diferenciação entre as nomenclaturas Dificuldade e Transtorno, seus tipos e causas. Sobre o processo ensino aprendizagem, percebe-se que há um grande desejo de alguns de se ter uma prática que não seja unilateral, na qual haja interação entre professor e estudante. Embora eles admitam não ser fácil, diante de tantas dificuldades que a educação apresenta, agora ficou claro para eles que as DA e TA se configuram como um desses obstáculos.

Quanto aos desafios enfrentados pelos professores em sala de aula, o maior deles é lidar com as grandes diferenças encontradas em sala de aula, em relação aos níveis de aprendizagem e o receio de "baixar o nível" das suas aulas, ou seja, equalizar o particular com a maioria. Nesta situação, de um modo geral, e de acordo com os achados, não há inclusão, o particular fica invisível. Outro desafio a ser enfrentado pelos sujeitos da pesquisa são as limitações do tempo e estrutura do sistema educacional. No mundo contemporâneo que se vive, precisa-se entender a atual situação da educação no país, e nessa análise deve-se ter um olhar crítico frente a inclusão de alunos com necessidades educativas específicas, seja no ensino regular ou nas universidades.

Torna-se pertinente compreender o significado de Transtornos e Dificuldades de Aprendizagem, visto que os indivíduos que as possuem precisam de adequações no processo de ensino para que obtenham êxito em sua aprendizagem. Todavia, compreender o que se entende por TA e DA não é tarefa fácil, porém não é impossível e muito menos diz respeito exclusivamente ao professor.

Esta pesquisa revelou que os professores, sejam eles bacharéis ou licenciados, possuem uma limitação sobre como perceber os estudantes que possuem uma ruptura na sua aprendizagem; porém 
fica claro a importância de se ter este conhecimento, pois dessa forma irá contribuir tanto para o seu desenvolvimento enquanto profissional e educador, quanto será condição necessária para a produção de práticas pedagógicas que incluem e facilitam a vida daqueles que, seja por uma dificuldade ou transtorno da aprendizagem, não conseguem ter uma aprendizagem efetiva.

\section{Referências}

ALMEIDA, R. M de. As dificuldades de aprendizagem: repensando o olhar e a prática no cotidiano da sala de aula. Dissertação (Mestrado em Engenharia de Produção e Sistema) - Universidade Federal de Santa Catarina, Florianópolis, 2002.

AMERICAN PSYCHIATRY ASSOCIATION (APA). Diagnostic and statistical manual of mental disorders. 2 ed. Washington: American Psychiatry Association; 2002.

BAllone, G. J.; MOURA, E. C. Problemas emocionais na escola, Parte 1. Disponível em: <http://www.psiqweb.med.br>. Acesso em: 14 fev. 2014.

CLASSIFICAÇÃO DE TRANSTORNOS MENTAIS E DE COMPORTAMENTO DA CID-10: descrições clínicas e diretrizes diagnósticas. Organização Mundial de Saúde. Porto Alegre: Artes Médicas, 1993.

DAVIS, C.; OLIVEIRA, Z. M. R. Psicologia na educação. 3 ed. São Paulo: Cortez, 2010.

FONSECA, V. Insucesso escolar - abordagem psicopedagógica das dificuldades de aprendizagem. Lisboa: Âncora Editora, 2004.

GENTILI, P.; ALENCAR, C. Educar na esperança em tempos de desencanto. Petrópolis: Vozes, 2001.

MATURANA, H.; REZEPKA, S.N. Formação e humana e capacitação. 5. ed. Rio de Janeiro: Vozes, 2008.

MEDEIROS, T. A polêmica da ritalina contra a inquietação na vida escolar. Disponível em: $<$ http://drauziovarella.com.br/dependencia-quimica/ritalina-contra-a-inquietacao-na-vida-escolar/> . Acesso em 21 nov. 2012.

MINAYO, M. C. S. Pesquisa social: teoria, método e criatividade. 29 ed. Petrópolis: Vozes, 2010.

PROENÇA, M. Problemas de aprendizagem ou problemas de escolarização? Repensando o cotidiano escolar à luz da perspectiva Histórico-Cultural. In: OLIVEIRA, M. K.; REGO, T. C.; SOUZA, D. T. R. Psicologia, educação e as temáticas da vida contemporânea. (Educação em Pauta: Teorias e Tendências). São Paulo: Moderna, 2002.

REBELO, J. Dificuldades da leitura e da escrita em alunos do ensino básico. 2. ed. Porto: Edições Asa, 2001. 
ROHDE, L. A.; BARBOSA, G.; TRAMONTINA, S.; POLANCZYK, G.. Transtorno de déficit de atenção/hiperatividade. Rev. Bras. Psiquiatr. [online]. 2000, v. 22, suppl. 2, p. 07-11. Disponível em: <http://dx.doi.org/10.1590/S1516-444620000006000 039>. Acesso em: $1^{\circ}$ maio 2012.

ROTTA, N. T.; OHLWEILER, L; RIESGO, R. S. Transtornos da aprendizagem: Abordagem neurobiológica e multidisciplinar. Porto Alegre: Artmed, 2006.

SCHIRMER, C. R.; FONTOURA, D. R.; NUNES, M. L. Distúrbios da aquisição da linguagem e da aprendizagem. Jornal de Pediatria, v. 8, n. 2, supl. 2004.

SCOZ, B. Psicopedagogia e realidade escolar: o problema escolar e de aprendizagem. Petrópolis: Vozes, 2004.

SISTO, P. P.; MARTINELLI, S. C. Afetividade e dificuldade de aprendizagem: uma abordagem psicoeducacional. São Paulo: Vetor, 2006.

SMITH, C.; STRICK, L. Dificuldades de aprendizagem de A a Z: um guia completo para pais e educadores. Porto Alegre: Artes Médicas, 2003.

\section{Como Citar esse artigo (ABNT):}

DAMASCENO, Mônica M.S. e GOMES, Annatália M.A. Transtornos de Aprendizagem na visão dos Professores. Id on Line Revista de Psicologia, Julho de 2014, vol.8, n.23, p. 57-72 ISSN 1981-1179. 